\title{
Predictors of Food Security among Vegetable Farmers in South Ketu and North Ketu, Ghana
}

\author{
Samuel A. Manu, Samuel Akuamoah-Boateng, Selorm Akaba \\ Department of Agricultural Economics and Extension \\ University of Cape Coast, Cape Coast, Ghana \\ E-mail:koffimanu@yaboo.com
}

\begin{abstract}
This study set out to find the predictors of food security for vegetable producing households in the Ketu Districts of the Volta Region of Ghana. In the study area, 226 heads of vegetable farming households were purposively interviewed. The data was subsequently analysed with both food security scale score and logistic regression analysis to determine each household's food security category. The study found eight variables as the major predictors of food security; they are: age, number of children, land ownership, access to change agent, access to financial services, number of vegetables produced, amount of credit received and vegetable produce markets. It is important that change agents focus on these factors among families to improve the availability of nutritious and adequate food in households. The other implication is that the improvement of elements such as amount of credit received and the location of vegetable markets can increase food security levels in the study site and extrapolation in other vegetable producing farm areas in the country.
\end{abstract}

Keywords: Food security; predictors; credit; extension agent; land size .

\section{Introduction}

In this section we will look at the rationale or justification for the study of food insecurity, the overarching determinants of food security and literature on the meaning of food insecurity. The context of vegetable farming is multiple pronged: production under rain fed conditions needs to succeed every farming season, productivity with traditional hoe and cutlass has to be high and maintained at those levels, and supplies to local markets have to bypass poor roads, moreover, farmers must get prices for their produce at a premium to make them content. These aforementioned features and weaknesses of rain fed agriculture require one to study food insecurity in order to find a panacea.

Other rationales for this paper are inadequate food supply at the rural level and even in urban areas, uneven distribution of food, poor persons' inaccessibility to food, market failures, commercialization of farmlands and their conversion to residential plots, and women's low access to and ownership of land or land disenfranchisement: all these necessitate a study of food security. One other essential reason is farmers' desire to achieve food security to protect their families.
This paper aims to examine this final context and to attempt to predict the factors which will induce food security. The novelty or new knowledge ensuing from this paper is in our analytical section where one is able to isolate and be precise about the factors triggering food insecurity. Should these predictors be confronted by local district assemblies, extension officers and policymakers, the nation will get gains in the creation of food security.

Food security has been defined as a situation where all people, at all times, have physical, social and economic access to sufficient, safe and nutritious food that meet their dietary needs and food preferences for an active and healthy life (FAO, 2004). In Ghana, the Ghana Food and Agricultural Sector Development Policy document (2004) defines food security as "good quality, nutritious food, hygienically packaged, and attractively presented, available in sufficient quantity all year round, located at appropriate places at affordable prices."

\section{The problem statement and study objectives}

Most residents in the Ketu municipality rely on vegetable production as a source of livelihood owing to a favourable soil type and tube-well irrigation 
prevalent and adopted by residents. However, Ghana and the study area of Ketu face the problem of lagged progress in food security because average yields have remained stagnant. As previous work shows, food security is defined as a situation where all people, at all times, have physical, social and economic access to sufficient, safe and nutritious food that meet both their dietary needs and food preferences for an active and healthy life (FAO, 2004). This is not the situation in the Ketu area.

In Ghana, the Ghana Food and Agricultural Sector Development Policy document (2007) defines food security as "good quality, nutritious food, hygienically packaged, and attractively presented, available in sufficient quantities all year round, located at appropriate places at affordable prices.” Other explanations assert that: food security is dependent on agricultural production, food imports and donations, employment opportunities and income earnings, intra-household decision making and resource allocation, health care utilisation and caring practices, (Maxwell and Frankenberger, 1992). However, household food security issues cannot be seen in isolation from broader factors such as physical, policy and social environment (Hoddinott, 2001).

The physical factors play a role in determining the activities that can be undertaken by rural households to achieve food security. Government policies, on the other hand, have a strong effect. Likewise, an unfavourable social environment, expressed in terms of mistrust of other social groups or even outright violence also determines food security. Since the problem of food insufficiency persists in the Ketu study and still this problem must be investigated in order to help peasant farmers out of poverty, it is hypothesized in this paper that some farm and household characteristics such as family size, land holdings, level of agricultural production, gender and age of household heads have got relative importance in the determination of whether a household is food secure or not.

The conditions under which food security or food insecurity is achieved will help one in applying the conditions to other study types such as tuber, cereal, or grain farmers.

The research questions and objectives or line of inquiry are as follows:

(i) What are the demographic characteristics of vegetable producing households?

(ii) What are the production characteristics of vegetable producing households in terms of
a.
types of vegetables produced by households,
b. number of different types of vegetables produced,
c. land ownership,
d. size of farm enterprise,
e. sources of finance,
f. point of sale and
g. access to change agents?

(iii) What is the food security status of vegetable producing households in the area?

(iv) What are the determinants of the food security status among vegetable producing households?

\section{Methodology}

A combination of three methodologies each with its strengths was used to assess the food security condition of vegetable farming households. First respondents were purposively sampled by selecting household heads since they are the best members in a household to give adequate information on the level of household food security. Two hundred and twenty-six heads of the vegetable farming households, therefore, were, selected and data collected on them by means of questionnaires and personal observations.

Second the food security classification of each household was measured by means of the 18-item household food security questionnaire approach (Item Response Theory Model) designed by Bickel et al (2000) and Johnson (2004). The choice and validity of the IRT as a measure of food security for the study was necessitated by the fact that the instrument has been shown to be a valid and reliable measure of food security status in especially English speaking countries (Gulliford et al.,2004; Frongillo, 1999, Gulliford et al., 2004, Perez-Escamilla et al., 2004, Alvarez et al., 2006).

The results of this instrument provided scores representing the food security status of the households. The food security scale score was then used to determine the households' food security category. The food security status indicates whether the household is food secure, food insecure without hunger, food insecure with hunger (moderate or severe). Moreover, one identifies potential indicators of food security through reading of the literature and through the authors' knowledge of the study. The indicators signifying whether a household is food 
secure or not are: age, family size/number of children, land ownership, land size, access to change agents, number of vegetables produced.

As a corollary to the selection of indicators, we needed to eventually come out with variables best as being predictors of household food security status; this need called for a logistic regression equation constructed with food security as the dependent variable. Although, conventionally regression analysis is widely used in most economic and social investigations, results from linear regression may lead to unreasonable estimates when the dependent variable is dichotomous. The use of the logit or probit models is recommended as a panacea of the drawback of the linear regression model (Gujarati, 2003). The dependent variable, in this case food security, was a binary variable which took a value of (1) if a household was found to be food secure and zero (0) if otherwise. The cumulative logistic probability model could be econometrically specified as:

$\log _{\mathrm{e}}\left[\mathrm{P}_{\mathrm{i}} / 1-\mathrm{P}_{\mathrm{i}}\right]=\beta_{0}+\beta_{\mathrm{t}} \mathrm{X}_{\mathrm{i}}+\varepsilon$.

Where $\mathrm{p}_{\mathrm{i}}$ is the probability that an individual household is food secure.

$\mathrm{X}_{\mathrm{i}}$ is the ith explanatory variable.

$\beta_{0}$ and $\beta_{1}$ are regression parameters to be estimated.

$\mathrm{e}$ is the natural logarithm and

$\varepsilon$ is the error term.
1. $\log _{e}\left[\frac{F S}{1-F S}\right]=\beta_{0}+\beta_{\mathrm{t}} \mathrm{X}_{\mathrm{i}}+\mathrm{e}$.

Where;

FS is the household food security status;

$\beta_{0}$ is the constant $\beta_{1}$ is the regression coefficient of $\mathrm{X}_{\mathrm{i}}$; and $e$ is the error term.

\section{Results and discussions}

Socio-Economic and Demographic Characteristics of Vegetable Producing Households in the Ketu Districts

\subsection{Age distribution of respondents}

The results of the study showed that the ages of the farmers ranged from 24 to 70 years. The mean age was about 40 years with a standard deviation of 9.166 and modal age of 35 years (Table.1). The study also revealed that younger people (between 20-49 years) are more involved in the vegetable production industry than the aged (that is above 50 years). The situation is not surprising since vegetable farming is both a capital and labour intensive investment.

Table 1

Age distribution of farmers

\begin{tabular}{lccc}
\hline Age range (years) & Frequency & Percent & Cumulative \% \\
\hline $20-29$ & 26 & 11.9 & 11.9 \\
$30-39$ & 97 & 44.5 & 56.4 \\
$40-49$ & 58 & 26.6 & 83.0 \\
$50-59$ & 29 & 13.3 & 96.3 \\
$60-69$ & 7 & 3.2 & 99.5 \\
$70-79$ & 1 & .5 & 100.0 \\
\hline Total & 218 & 100.0 & \\
\hline
\end{tabular}

Source: Field survey data, 2006

Mean $=39.9 \quad \mathrm{SD}=9.166 \quad$ Youngest $=24 \quad$ Oldest $=70$ 


\subsection{Major types of vegetablesproduced in the study area}

Of the eleven vegetable crops produced in the area, 6 were regarded as major vegetable crops. This is based on the frequency of cultivations, size of field allocated to a particular vegetable crop, consumers' demand for the crop and the level of economic benefits derived from it by the farmers.

A vegetable crop that is cultivated on continual basis (i.e. from season to season), on a relatively larger portion of available farm area and has a higher consumer demand was considered as a major vegetable crop while those cultivated infrequently, on a relatively smaller proportion of available farm area and a lower level of economic benefit, were considered a minor vegetable crop. Most respondents $(74.3 \%)$ regarded onion as major vegetable crop in the area.
About 10.3 percent and 5.6 percent mentioned tomatoes and green pepper as their major vegetable crop respectively. About an equal percentage of the respondents (about 4 percent) classified carrot and okra as their major vegetable crop while only 1.9 percent regarded spinach as their major vegetable crop (Figure 1).

It is not surprising that most respondents mentioned onion as their major vegetable crop since it is cultivated season after season and on a relatively higher proportion of available farm land in any season. It also has a higher consumer demand and ultimately resulting in a relatively higher level of economic benefit derived from it. To supplement their income, the farmers sometimes diversify onion production by growing other vegetables in the onion fields during off seasons.
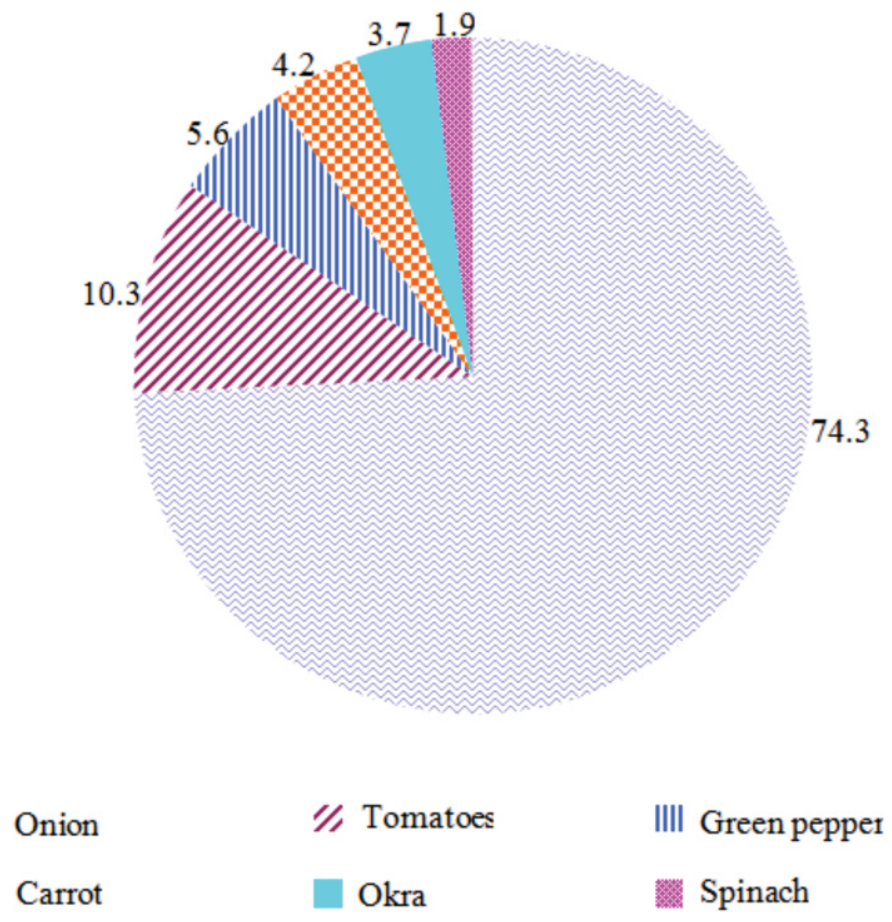

Source: Field survey data, 2006

Fig. 1: Percent respondents who classified the various vegetables as major

vegetables they have been producing in the study area.

\subsection{Sources offinance}

Finance plays a very important role in vegetable farming since it determines farmers' ability to secure the requisite resources for the establishment and maintenance of their farms. Access to credit for productive purposes can effectively reduce the vulnerability of poor households to food insecurity and improve their access to food. This importance of credit access therefore, necessitated the investigation of access to finance and financial services in the study area. Five main sources of finance for vegetable production were identified in the area (Table 2 ). 
Table 2

Main sources of finance for vegetable production $(n=226)$

\begin{tabular}{lll}
\hline Source & Frequency & Percent \\
\hline Own saving & 177 & 78.3 \\
Money lenders & 97 & 42.9 \\
Relatives and friends & 78 & 34.5 \\
Banks & 9 & 4.0 \\
Cooperatives/credit union & 4 & 1.8 \\
Financial NGOs & 1 & 0.4 \\
\hline
\end{tabular}

Source: Author's Field survey data, 2006

As shown in Table 2, 78.3\% rely mainly on their own funds for farming purposes while less than 50\% access financial support for their vegetable production activities from informal sources (moneylenders $42.9 \%$ and relatives and friends - 34.5\%). These findings of the study concur with work done by Markowski (2002) and Von Pischke (2002). Markowski (2002) reported that rural clients usually depend on locally based informal sources such as family, friends or moneylenders, who lend only small amounts for short periods of time. On his part, Von Pischke (2002) asserted that even though informal credit is sometimes regarded as exploitative, it is common in many countries.
4.4 Vegetable farmers' contacts with change agents in the studyarea

The results of analysis in table 6 showed that only $61.1 \%$ of the 226 respondents had access to change agents. More than half (57.2\%) of these respondents who ever had access to the change agents started working with the change agents for less than 6 years and $31.2 \%$ of them had been working with the change agents from six to ten years.

\section{Table 3}

Number of years the vegetable farmers have been working with the change agents)

\begin{tabular}{cccc}
\hline Years with change agents & Frequency & Percent & Cum. Percent \\
\hline Not yet & 88 & 38.9 & 38.9 \\
$<6$ & 79 & 35.0 & 73.9 \\
$6-10$ & 43 & 19.0 & 92.9 \\
$11-15$ & 10 & 4.4 & 97.3 \\
$16-20$ & 6 & 2.7 & 100.0 \\
\hline Total & 226 & 100.0 & \\
\hline
\end{tabular}

Source: Author's Field survey data, 2006 
The main sources of technical knowledge for farmers are the research stations and research findings communicated to the farmers through the Ministry of Food and Agriculture (MoFA) frontline staff, non-governmental organizations (NGOs), farmer- based organizations (FBOs) and community service organizations (CSOs). An important attribute of extension education as illustrated by La Anyane (1985) is that it provides a technique for the enhancement of the chances for increase in production without any significant quantitative increases in the basic factors of production: land, labour and capital.

\subsection{Securitystatus of vegetableproducing housebolds}

Following the guide to measuring household food security by Bickel et al. (2000) and Johnson (2004), the households of the respondents were accordingly classified under "food secure", "food insecure without hunger" and "food insecure with hunger".

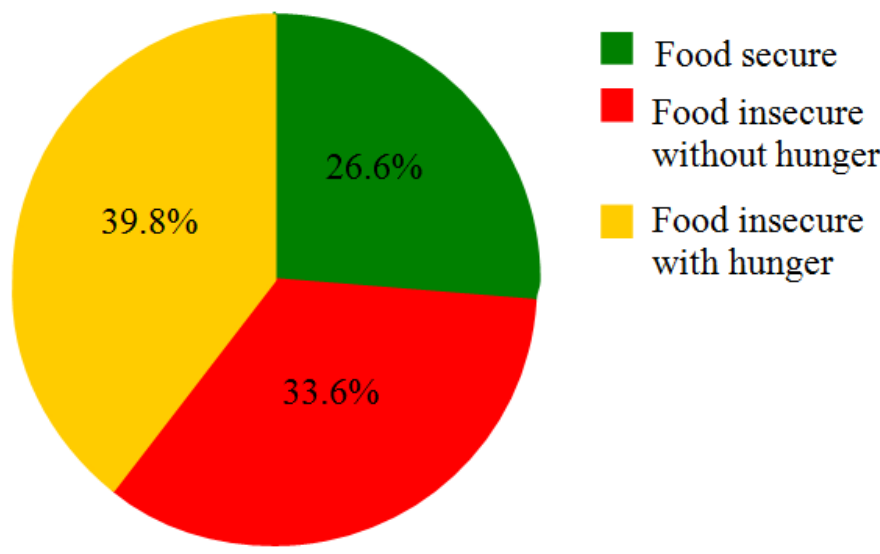

Source: Field survey data, 2006

Fig. 2: Classification of respondents' households into food security categories

Table 4

Logistic regression of selected independent variables on food security levels of the vegetable farming households

\begin{tabular}{lrllll}
\hline Explanatory variables & \multicolumn{1}{l}{ B } & S.E.E & Wald & Sig. & Odd Ratio \\
\hline Constant & -12.670 & 4.034 & $9.865^{* *}$ & 0.002 & 0.000 \\
Age $\left(\mathrm{X}_{1}\right)$ & 1.513 & 0.565 & $7.176^{* *}$ & 0.007 & 4.542 \\
Marital status $\left(\mathrm{X}_{2}\right)$ & 0.914 & 0.726 & $1.585^{\text {ns }}$ & 0.208 & 0.401 \\
No. of Children $\left(\mathrm{X}_{3}\right)$ & -1.513 & 0.682 & $4.930^{*}$ & 0.026 & 0.220 \\
Land ownership $\left(\mathrm{X}_{4}\right)$ & 2.053 & 0.953 & $4.645^{*}$ & 0.031 & 7.794 \\
Land Size $\left(\mathrm{X}_{5}\right)$ & 1.329 & 0.828 & $2.570^{\mathrm{ns}}$ & 0.109 & 3.779 \\
Access to change agents $\left(\mathrm{X}_{6}\right)$ & 1.948 & 0.885 & $4.844^{*}$ & 0.028 & 7.015 \\
Sources of finance $\left(\mathrm{X}_{7}\right)$ & -5.274 & 1.517 & $12.090^{* *}$ & 0.001 & 0.005 \\
No. of vegetables $\left(\mathrm{X}_{8}\right)$ & 0.558 & 0.231 & $5.854^{*}$ & 0.016 & 1.747 \\
\hline
\end{tabular}




\subsection{Modelsummary:}

-2 Log likelihood = 23.126; Cox \& Snell R Square

$=0.414$;

Nagelkerke R Square $=0.738$

ns $=$ no significant difference exist $*=$ significant at $0.05 * *$ significant at 0.01

Source: Field survey data, 2006

\subsection{Regression equation for food security}

With the use of this set of nine predictors, the logistic regression equation for the log-odds in favour of food security is estimated to be

$$
\begin{aligned}
& \log _{e}\left[\frac{F S}{1-F S}\right]=-12.670+1.513 X_{1}+0.914 X_{2}-1.513 X_{3}+ \\
& 2.053 X_{4}+1.329 X_{5}+1.948 X_{6}-5.274 X_{7}+0.558 X_{8}
\end{aligned}
$$

As table 7 depicts, eight independent variables (age, number of children, land ownership, access to change agent, access to financial services, number of vegetables produced, marital status, and land size) accounted for $73.8 \%$ of all the variance in the food security levels of vegetable farming households. The amount of contribution of the ten variables made towards the variance in the food security levels is shown in the Nagelkerke $\mathrm{R}$ Square column in the model summary (Table 7).

The Wald chi-squared statistics, as taken from the table, are not significant for marital status and land size (i.e., p-values of 0.208 and 0.109 respectively), whereas the chi-squared values for the six explanatory variables are significant at the $\alpha=0.05$. Thus, given that the three predictors remain in the model, the removal of any of the rest of the seven (i.e. age, number of children, land ownership, access to change agent, access to financial services, and number of vegetables produced) as a predictor will result in significantly poorer predictive efficiency, although removal of any of the other two predictors (marital status and land size) would not have a significant impact.

The individual values of the Standard Error of Estimate (S.E.E) also show a relatively high accuracy of prediction in the regression model $(0.231 \geqslant$ S.E.E $\leqslant 1.517)$. It can, therefore, be deduced that an improvement in such variables as access to change agents, sources of finance, land size, land ownership and number of vegetables produced will go a long way to have a positive impact on the food security levels of the vegetable farming households.

\section{Conclusions}

Calculations with the use of the IRT indicators (Bickel et al., 2000), indicates-that the vegetable farmers in the Ketu District can generally be considered food insecure (73.4\%). The food insecure households with children were able to sacrifice adults' food consumption to maintain adequate levels for their children.

The overall predictors for the levels of food security are age, number of children, land ownership, access to change agent, access to financial services, number of vegetables produced, amount of credit received, marital status, land size and where the vegetable produce are sold. These variables accounted for about $78 \%$ of all the variance in the food security levels of vegetable farming households.

The implication is that any improvement in the variables such as access, amount of credit received, land size and where the vegetable produced are sold can go a long way to increase food security levels of the vegetable-farming households in the study area. The main findings of the empirical analysis indicated that age of household heads has a significant influence on food security status at the household level, because the head's age enhances experience regarding the provision of proper and required food for the family, since the head understands better the requirements of food with respect to family's age, gender and workload.

\section{References}

FAO, (1996). Rome Declaration on World Food Security and World Food Summit Plan of Action, World Food Summit, 13 - 17 November 1996, Rome.

FAO, (1983). World Food Security: A Reappraisal of the Concepts and Approaches, Director General's Report, Rome.

Bickel, G., Nord, M., Price, C., Hamilton, W. and Cook, J., (2000). Guide to Measuring Household Food Security (Revised). U.S. Department of Agriculture, Food and Nutrition Service: Office of Analysis, Nutrition, and Evaluation. 
Gulliford, M. C., Mahabir, D., Rocke B., (2004). Reliability and Validity of A Short Form Household Food Security Scale in a Caribbean Community, BMC Public Health,Jun Vol. 16, No. 4, pp.22.

Frongillo, E. A.,(1999). Validation of Measures of Food Insecurity and Hunger, Journal of Nutrition, Issue 129, pp.506s -509s.

Perez -Escamilla, R., Segall -Correa, A., Kurdian, M., Maranha, L., Sampaio, M. F. A., Marin -Leon, L. and Panigassi, G., (2004). An Adapted Version of the U. S. Department of Agriculture Food Insecurity Module Is a Valid Tool for Assessing Household Food Insecurity in Campinas, Brazil. Community and International Nutrition. The American Society for Nutritional Sciences, Journal of Nutrition., Issue 134, No. $1923-1928$.

Alvarez M. C., Estrada A., Montoya E. C. and Melgar -Quinonez H., (2006). Validation of a Household Food Security Scale In Antioquia, Colombia, Salud PublicaMex., Vol. 48, No. 6, pp. 474-81.
Markowski, P., (2002). Microfinance Innovations in the Gulf of Guinea Region. In Food Security in a Changing Africa. Centre for Applied studies in International Negotiations, Geneva.

Von Pischkle, J. D., (2002). So Much Progress in Agricultural and Finance, So Little in Rural Credit: Proposals for Constructive Engagement. In Food Security in a Changing Africa, Centre for Applied Studies in International Negotiations, Geneva.

La Anyane, S., (1985). Economics of Agricultural Development in Tropical Africa, John Wiley and Sons.

Johnson, M. S., (2004). IRT Models and Their Use in Measuring Food Insecurity and Hunger. Paper presented at the Workshop on the Measurement of Food Insecurity and Hunger, July 15, 2004. Panel to Review USDA's Measurement of Food Insecurity a n d H u n e r. A vaila ble online:http://www7.nationalacademies.org/cnstat /Johnson\%20paper.pdf

Extreme Response (2008). World Statistics: Hunger and Poverty. Available online at: http://extremeresponse.org/statistics/ 